Research Article

\title{
A psychological aspect of malnutrition: hitting psychological distress among patients with depression
}

\begin{abstract}
Nutrition plays a vital role in mental health; malnutrition kills the mental health of individuals and psychological distress is a sign of poor mental health. The purpose of current research to explore the association between malnutrition and psychological distress and it was also aimed to determine the gender differences on malnutrition and psychological distress among adults. Randomly 100 diagnosed patients aged between 25-35years were taken from different hospitals of Multan. Malnutrition was assessed by Malnutrition Screening Tool $^{1}$ and psychological distress was measured by Kessler Psychological Distress Scale. ${ }^{2}$ Statistical analysis explored that malnutrition has positive relationship with psychological distress and malnutrition has impact on psychological distress. Findings of present research also depict that malnutrition and psychological distress has significant gender differences among adults. Female patients scored high on malnutrition and male patients showed high level of psychological distress. The implication of current research that food intake must be healthy because healthy food is key path to good health and mental health. Seminars and workshops on healthy nutrition plans must be conducted to overcome the side effects of malnutrition in individuals.
\end{abstract}

Keywords: malnutrition, psychological distress, mental health, healthy food, nutrition plans
Volume 6 Issue 7 - 2016

\author{
Momina Abid \\ Department of Applied Psychology Bahauddin Zakariya \\ University, Pakistan
}

Correspondence: Momina Abid, Department of Applied Psychology Bahauddin Zakariya University, Multan, Pakistan, EmailmominaabidII@gmail.com

Received: June 20,2016 | Published: December 28, 2016

\section{Psychological distress}

Psychological distress is viewed as an emotional condition that involves negative views of the self, others and the environment and is characterized by unpleasant subjective states such as feeling tense, worried, worthless and irritable. ${ }^{3}$ These subjective states can reduce the emotional resilience of individuals and impact on their ability to enjoy life and to cope with pain, disappointment and sadness. Psychological distress can be viewed as a continuum in which people can move from experiencing wellbeing to distress and back at various times throughout their lives. ${ }^{4,5}$ The following are the medical and cognitive theoretical perspectives of psychological distress.

\section{Medical model}

Pathology is a prevalent perspective of medical model..$^{5,6}$ In accordance to medical model psychological distress is considered as an illness in the same classification as whatever other physical sickness, this model uses comparable model in characterizing psychological distress as that utilized by restorative professionals. As such, psychological distress is some type of neurological imperfection in charge of the scattered thinking and conduct, and requires medicinal treatment and consideration. ${ }^{7}$

\section{Cognitive theory}

Cognitive model define psychological distress as the process of negative thinking and perception. ${ }^{8}$ This process is reflected in the case distressed patients have in general a negative vision on themselves, their environment and in the future. ${ }^{9}$ They consider themselves as nothing valuable, inappropriate and inadequate.

\section{Malnutrition}

Malnutrition has been perceived as a nationwide trouble. ${ }^{10}$ Malnutrition is often not identified in hospitalized patients and can unfortunately lead to increased risk for complications such as morbidity, increased length of stay, increased mortality, functional impairment, and economic implications. ${ }^{11-13}$

Research survey carried by Norman et al., ${ }^{14}$ expressed that malnutrition linked to the predictive entailments of illness. A growing body investigations explored that no changing were found in the prevalence of malnutrition from 1990, in U.S. and the Europe researchers conclude that in hospitals the ratio of malnourished or at nutritional risk about $31 \%$. Morbidity of malnutrition increasing due to some causes in which marred immune functioning and delayed healing of wounds are most common. ${ }^{14}$

Only one study have done with In a study conducted by Ma, Poulin, Feldstain \& Chasen, ${ }^{15}$ the researchers found that there is a positive relationship between malnutrition and psychological distress, and malnutrition as a predictor of psychological distress.

\section{Rational of the study}

More important part of health is mental health; no health without mental health". (World Health Organization, 2010). Mental health issues are increased day by day in every individual and it affects 1 in 4 people. Malnutrition is a common, under-recognized and undertreated condition. It is in seeing that half of five deaths in worldwide due to malnutrition. Pakistan is 7th most populated country in the world and unfortunately has high prevalence of communicable disease like malnutrition. It is not only effect on psychical health also a huge effect on psychological health and functioning. Present research proposed to accomplish with the limitation of previous research by. ${ }^{15}$ Current study focused to explore the impact of malnutrition on psychological distress and also find out the differences in malnutrition and psychological distress in term of gender.

\section{Objectives}

a. To explore the relationship of malnutrition with psychological distress among patients with depression. 
b. To assess the impact of malnutrition on psychological distress among patients with depression.

c. To investigate gender differences in malnutrition and psychological distress among patients with depression.

\section{Hypothesis}

A. Malnutrition positively correlated with psychological distress among patients with depression.

B. Malnutrition has significant impact on psychological distress among patients with depression.

C. Malnutrition will be high among female patients as compare to male patients.

D. Psychological distress will be high among male patients than female patients.

Table I Pearson Product Correlation between Malnutrition and Psychological Distress

\begin{tabular}{lr}
\hline Psychological Distress \\
\hline Malnutrition $\quad .520^{* * *}$
\end{tabular}

Note. $\mathrm{N}=100 . * * \mathrm{p}<0.01$

\section{Operational Definition}

Malnutrition: Malnutrition refers to a deficiency, excess or imbalance of a wide range of nutrients, resulting in a measurable adverse effect on body composition, function and clinical outcome. ${ }^{16}$

Psychological Distress: Psychological distress can be defined as "the unique discomforting, emotional state experienced by an individual in response to a specific stressor or demand that results in harm, either temporary or permanent, to the person". ${ }^{17}$

\section{Methods}

\section{Participants}

Randomly 100 diagnosed patients were taken from different hospitals of Multan. 50\% female and 50\% male with age range of 25-35years participated in the study. All participants were educated. Socioeconomic status of participants was same.

\section{Instruments}

One Instrument used in the current study.

i. Malnutrition Screening Tool

ii. Kessler Psychological Distress Scale

Malnutrition Screening Tool: Malnutrition screening tool was developed by Ferguson et al., in 1999. It is a very simple nutrition screening tool based on weight loss and appetite changes and check nutrition status very quickly. Greater than 2 score shows high risk of malnutrition.

Kessler Psychological Distress Scale: This instrument was formulated by Kessler et al., in 2003 to evaluate the level of psychological distress in individuals. Kessler Psychological Distress Scale consisted on 10 items. Each item related to emotional states with a 5 point likert scale. Total score based on sum of all the items. High score indicating high level of psychological distress and low score pertain to low level of psychological distress.

\section{Procedure}

Data collection was accomplished by the utilization of 2 questionnaires along with informed consent, distributed to the 100 diagnosed patients aged between 25-35years were taken from different hospitals of Multan. Participants were willing to take part in research and all the participants were informed about the purpose of the research and they also allow for leave the research any time if they don't feel comfortable. They was recommended to fill all the items honestly and assured about the confidentiality. Data analysis of the current study was done through the 22 version of SPSS (Statistical Package for Social Sciences).

\section{Results}

Data analysis was done by 22 Version of SPSS. Pearson Product Correlation was used to explore the relationship between malnutrition and psychological distress. Liner regression was employed to see the impact of malnutrition on psychological distress. In present study, Independent sample t- test was utilized to find out the gender differences on malnutrition and psychological distress.

Table 1 indicates that significant positive relationship between malnutrition and psychological distress $(\mathrm{r}=.520, \mathrm{p}<0.01)$ showing that if malnutrition increase in adults psychological distress will also increase in adults and if malnutrition decrease psychological distress will also decrease in adults. Results of correlation supported the hypothesis.

Values as above in Table 2 depict that positive liner relationship between malnutrition and psychological distress. Malnutrition has significant impact on psychological distress among adults. Findings supported the hypothesis of research (Table 3).

Finding indicates in Table 4 that significant differences were founded among male and female adults on malnutrition and psychological distress. Finding depicts that female adults score high on malnutrition and psychological distress as compare to male adults. Hypothesis of current study accepted (Figure 1).

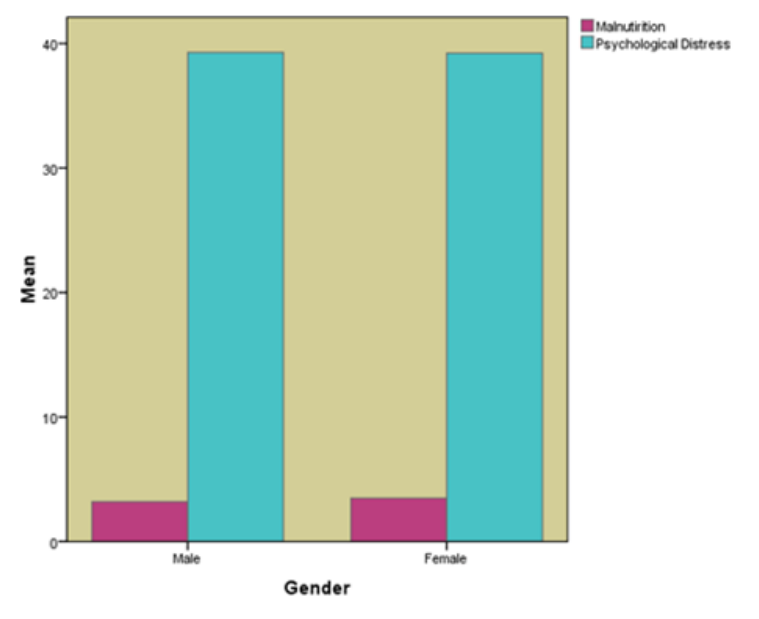

Figure I Bar Graph indicating Gender Differences on Malnutrition and Psychological Distress.

\section{Discussion}

The major objective of current research was to explore the impact of malnutrition on psychological distress among patients with depression and it was also hypothesized that level of malnutrition 
will be high in female patients and level of psychological distress will be high among male patients. Finding revealed that malnutrition and psychological distress positively correlated to each other's and findings also explored that malnutrition has significant impact on psychological distress. The findings of the research were in line with previous literature that demonstrated positive correlation between malnutrition and psychological distress. ${ }^{15}$ Therefore the hypothesis of current study accepted.

Next hypothesis based on the gender differences on the level of malnutrition among patients with depression. Research findings showed that significant gender differences were found in the level of malnutrition. Female patients scored high in the level of malnutrition than male patients.

Last hypothesis of present research was "Psychological distress will be high among male patients than female patients". Results of this research confirmed that male patients have high level of psychological distress as compare to female patients. Hence, research hypothesis is supported on behalf of present findings.

Table 2 Regression Analysis showing Impact of Malnutrition on Psychological Distress

\begin{tabular}{llllll}
\hline Predictor & B & Std. Error & $\boldsymbol{\beta}$ & T & P \\
\hline (Constant) & 26.996 & 2.124 & & 12.712 & 0 \\
Psychological Distress & 3.669 & 0.609 & 0.52 & 6.024 & 0 \\
\hline
\end{tabular}

Note. $R 2=0.270$, Adjusted R2 $=0.263,(F(I, 98)=36.292, * * * p<0.001$

Table 3 Means, Standard Deviations, and t-values along Gender on Malnutrition Screening Tool and Kessler Psychological Distress Scale $(\mathrm{N}=100)$

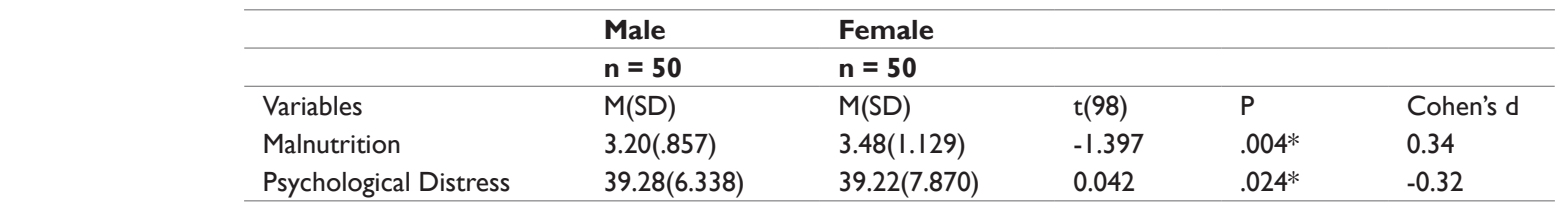

Note. $\mathrm{N}=100 . *_{\mathrm{p}}<0.05$

\section{Conclusion}

Present study concluded that nutrition plays a vital role in mental health of individuals. Findings of study confirm that malnutrition has significant positive relationship with psychological distress and also conclude that malnutrition has significant impact on psychological distress. If malnutrition increases the level of psychological distress will also increase. Finding depicts that significant gender differences were found in this study. Female have high level of malnutrition as compare to males but male shows greater level of psychological distress than females.

\section{Implication of the study}

The implication of current research that food intake must be healthy because healthy food is key path to good health and as well as mental health. Seminars and workshops on healthy nutrition plans must be conducted to overcome the side effects of malnutrition in individuals.

\section{Directions for future Research}

a. Sample of the research must be increased to the purpose of generalization.

b. This research is based on cross sectional research design; in future it must be conducted with longitudinal research design.

c. The major limitation of the current research it's a correlational research; Causal relationship must be find in next study because it's important to find out the casual factors that helps to play role in malnutrition and psychological distress.

\section{Acknowledgments}

None.

\section{Conflicts of interest}

Author declares there are no conflicts of interest.

\section{Funding}

None.

\section{References}

1. Barlow D, Durand V. Abnormal psychology. (2nd edn). Pacific Grove. Brooks/Cole. 1991.

2. Barlow D, Durand V. Abnormal Psychology: An integrative approach. Belmont, CA: Thomson Wadsworth, USA. 2005.

3. Carson R, Butcher JN, Mineka S. Abnormal psychology in modern life (10th edn). New York: Harper Collins, USA. 1996.

4. Elia M. Guidelines for detection and management of malnutrition. Maidenhead: BAPEN, England. 2000.

5. Ferguson M, Capra S, Bauer J, et al. Development of a valid and reliable malnutrition screening tool for adult acute hospital patients. Nutrition. 1999;15(6):458-464.

6. Horwitz A, Scheid T. A handbook for the study of mental health. Cambridge: Cambridge University Press, USA. 1999.

7. Kaplan H, Sadock B. Synopsis of Psychiatry: Behavioral Sciences/ Clinical Psychiatry (8th edn). New Delhi: B.I. Waverly Pty. Ltd., India. 1998.

8. Kessler RC, Barker PR, Colpe LJ, et al. Screening for serious mental illness in the general population. Arch Gen Psychiatry. 2003;60(2):184-189.

9. Republic of Kenya. Sessional Paper No. 4 of 1981 on National Food Policy, Government Printer, Nairobi, Kenya. 1981.

10. Ridner SH. Psychological distress: concept analysis.J Adv Nurs. 2004;45 (5):536-545.

11. Norman K, Pichard C, Lochs H, et al. Prognostic impact of diseaserelated malnutrition. Clin Nutr. 2008;27(1):5-15.

12. Novello A. Abnormal Psychology: An Integrative Approach: A Workbook for South African Students. South Africa: International Thomson Publishing. 1999. 
13. Ma L, Poulin P, Feldstain A, et al. The association between malnutrition and psychological distress in patients with advanced head-and-neck cancer. Curr Oncol. 2013;20(6):e554-e560.

14. Moriana M, Civera M, Artero A, et al. Validity of subjective global assessment as ascreening method for hospital malnutrition. prevalence of malnutrition in a tertiary hospital. Endocrinol Nutr Engl Ed. 2014;61(4):184-189.

15. White JV, Guenter P, Jensen G, et al. Consensus statement of the Academy of Nutrition and Dietetics/American Society for Parenteral and Enteral Nutrition: characteristics recommended for the identification and documentation of adult malnutrition (under nutrition). J Acad Nutr Diet. 2012;112(5):730-738.
16. Weinrach S. Cognitive Therapist: A Dialogue with Aaron Beck. Journal of Counseling \& Development. 1988;67(3):159-164.

17. Wong S, Graham A, Hirani SP,et al. Validation of the Screening Tool for the Assessment of Malnutrition in Paediatrics (STAMP) in patients with spinal cord injuries (SCIs). Spinal Cord. 2013;51(5):424-429. 